\title{
Calculation of the stress intensity factor for arbitrary finite cracked body by using the boundary weight function method
}

\author{
CHIEN-CHING MA, I-KUANG SHEN \\ Department of Mechanical Engineering, National Taiwan University, Taipei, Taiwan 10617, Republic of \\ China \\ and \\ PWU TSAI \\ Chung-Shan Institute of Science and Technology
}

Received 13 October 1993; accepted in revised form 30 September 1994

\begin{abstract}
An efficient boundary weight function method for the determination of stress intensity factors in a twodimensional mixed mode cracked body with arbitrary shape and subjected to arbitrary loading is presented in this study. The functional form of the boundary weight functions for modes I and II are successfully demonstrated by using the least squares fitting procedure. Explicit boundary weight functions are presented for rectangular plates of finite width and length containing edge and central cracks. If the stress distribution of a cut out rectangular cracked plate from any arbitrary shape of cracked body subjected to arbitrary loading is determined, the stress intensity factors $K_{\mathrm{I}}$ and $K_{\mathrm{II}}$ for the cracked body can be obtained from the predetermined boundary weight functions by a simple integration. Comparison from the literature of the calculated results with some solutions by other workers confirms the efficiency and accuracy of the proposed weight function method.
\end{abstract}

\section{Introduction}

The calculation of stress intensity factors is of great significance for the design of structures containing cracks. Stress intensity factors are now available for a wide range of crack configurations and loadings and have been summarized in well-known handbooks of Tada et al. [1], Rooke and Cartwright [2] and Sih [3]. It is still found inadequate with regard to the needs in practical applications because actual structural details are often unique so that ready made handbook solutions cannot be available. There is a great need for simple methods to obtain stress intensity factors for engineering applications with good accuracy.

The weight function method which was first proposed by Bueckner [4], is a powerful and efficient method for determining the stress intensity factor. Rice [5] proposed a convenient procedure for weight function determination for plane problems. The weight functions serve as a universal function for a given crack geometry and composition; they are independent of applied loading. The weight function concept is, in fact, Green's function of the stress intensity factors for a cracked body. The weight function, once obtained from a single simple load case, can then be used to calculate additional stress intensity factors for the same cracked geometry but with different load conditions. In the original version of the weight function method, the boundary condition dealt with does not involve prescribed displacements. Recently Bowie and Freese [6] have made a reformulation for the weight function to include the mixed traction and displacement boundary condition case. In the study by Bortman and Banks-Sills [7], Rice's 
Table 1. The interpolation coefficients $C_{n}$ of the boundary weight function for a rectangular plate with central crack $\left(L / W=1, a / W=\frac{1}{4}\right)$ subjected to symmetric loading

\begin{tabular}{|l|r|l|r|}
\hline \multicolumn{4}{|c|}{$C_{n}\left(L / W=1, a / W=\frac{1}{4}\right)$} \\
\hline \multicolumn{2}{|c|}{ top in normal direction } & \multicolumn{2}{|c|}{ top in shear direction } \\
\hline 1 & $0.1706871605 \mathrm{D}+01$ & 1 & $0.2432206285 \mathrm{D}-03$ \\
2 & $0.4352540449 \mathrm{D}-01$ & 2 & $0.1993861591 \mathrm{D}+01$ \\
3 & $-0.4076352090 \mathrm{D}+01$ & 3 & $0.4212926804 \mathrm{D}+00$ \\
4 & $0.1598690348 \mathrm{D}+01$ & 4 & $-0.4890801747 \mathrm{D}+01$ \\
5 & $0.2070482503 \mathrm{D}+01$ & 5 & $0.4601678671 \mathrm{D}+01$ \\
6 & $-0.1368551849 \mathrm{D}+01$ & 6 & $-0.1312249006 \mathrm{D}+01$ \\
\hline side in normal direction & \multicolumn{3}{|c|}{ ide in shear direction } \\
\hline 1 & $-0.5969323598 \mathrm{D}+00$ & 1 & $0.6647082219 \mathrm{D}-03$ \\
2 & $-0.1430961157 \mathrm{D}+00$ & 2 & $-0.5544516863 \mathrm{D}+00$ \\
3 & $0.5133980170 \mathrm{D}+01$ & 3 & $0.2884617706 \mathrm{D}+00$ \\
4 & $-0.7411609027 \mathrm{D}+01$ & 4 & $0.3094232784 \mathrm{D}+01$ \\
5 & $0.5134254466 \mathrm{D}+01$ & 5 & $-0.5050166338 \mathrm{D}+01$ \\
6 & $-0.1301625739 \mathrm{D}+01$ & 6 & $0.2197213021 \mathrm{D}+01$ \\
\hline
\end{tabular}

displacement derivative definition of the weight function for mode I deformation has been extended to mixed fracture mode.

In recent years, the finite element method applied to fracture mechanics has been well developed. There are several studies that have sought to build up the calculation technique and provide a possible and efficient way to construct the weight functions for finite cracked bodies. Sha [8] used the stiffness derivative technique coupled with singular crack-tip elements to determine the weight functions, and he obtained the weight function for a single edge crack with specified specimen width and length by means of the finite element method. Sha and Yang [9] obtained the weight function for an oblique edge crack by means of the finite element method using the virtual crack extension technique as suggested by Parks [10] and Hellen [11]. They have extended this method to non-symmetric mixed mode problems and used a special symmetric mesh in the vicinity of the crack tip such that the stress intensity factors for modes I and II could be determined independently. Recently, Tsai and Ma [12] and Ma, Chang and Tsai [13] constructed the explicit form of the mixed mode crack face weight function for finite rectangular plates by using the finite element and curve fitting technique. These explicit weight functions are expressed in terms of a position coordinate, crack length, specimen width and length, which are certainly more useful in practical applications. However, the above mentioned crack face weight function method can only be used to determine stress intensity factors for specific cracked geometry.

A variational principle is introduced by Sham [14] and Sham and Zhou [15] for determining singular fields in finite bodies. A specialized form of this variational principle is employed to determine the Bueckner-Rice weight functions in two and three dimensions. A finite element implementation of the variational principle is given and this leads to a unified approach in the numerical computations of weight functions for all three fracture modes. Two-dimensional weight functions in arbitrary anisotropic solids under mixed boundary conditions are analyzed by Sham and Zhou [16] by using the finite element method introduced by Sham [14]. 


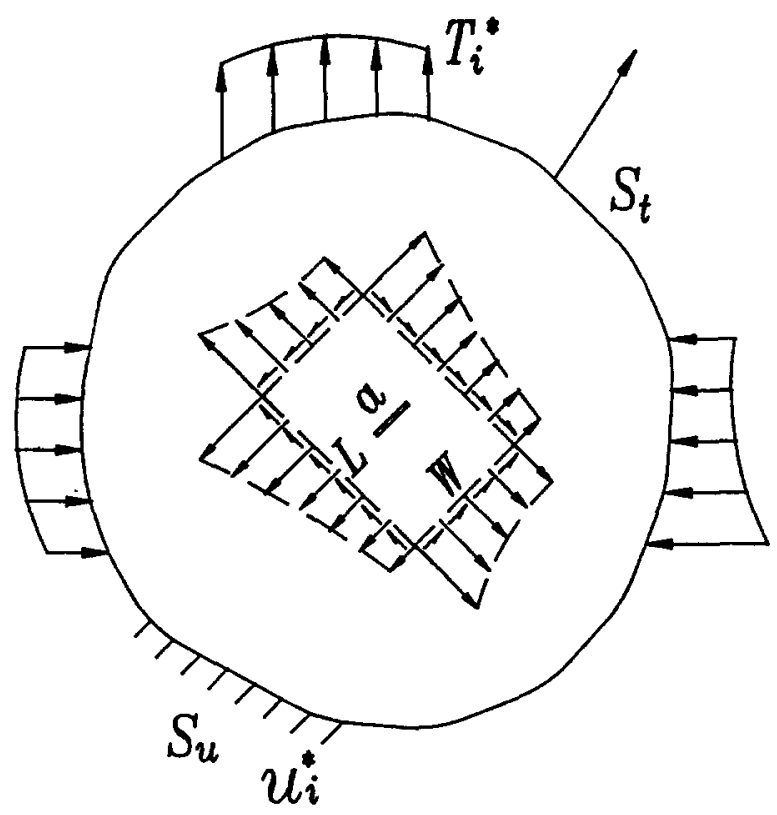

(a)

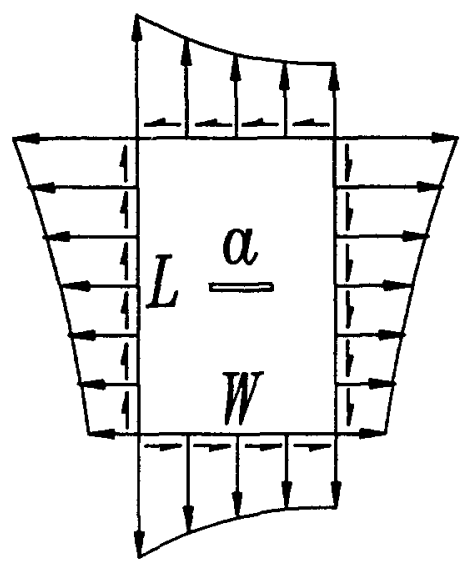

(b)

Fig. 1. (a) Geometry for a cracked body subjected to general boundary condition with a cut rectangular cracked plate containing a central crack; (b) Geometry of a rectangular cracked plate with a central crack as indicated in Fig. 1a.

The weight function method has also been studied for cracks in a homogeneous solid with anisotropic elastic properties by Kirchner [17], An [18] and Gao [19].

There are many techniques that can be used to calculate the stress intensity factor by finite element method, it usually needs a very fine mesh near the crack tip. In this paper, an efficient method which combines finite element with boundary weight functions has been established in determining mixed stress intensity factors for arbitrary crack geometry and subjected to arbitrary loadings. The stress intensity factor for any specific crack geometry subjected to general prescribed boundary conditions as shown in Fig. 1a is equal to that of the cut out rectangular cracked plate (Fig. 1b) with the same stress distribution on the cut out rectangular 


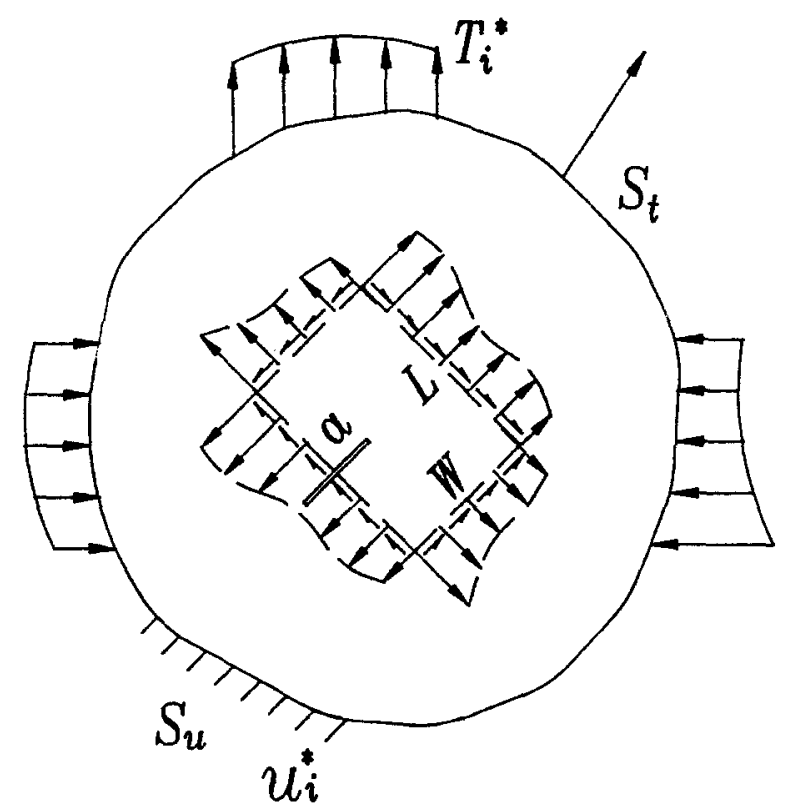

(a)

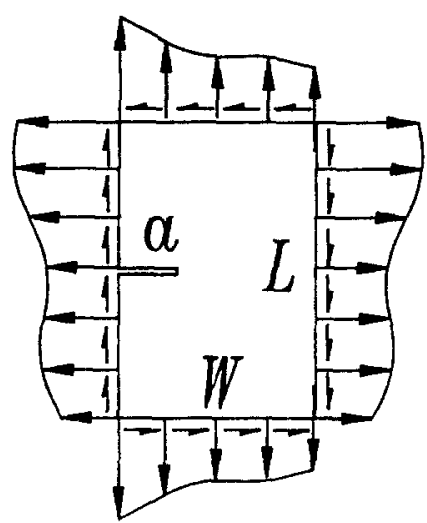

(b)

Fig. 2. (a) Geometry for a cracked body subjected to general boundary condition with a cut rectangular cracked plate containing an edge crack; (b) Geometry of a rectangular cracked plate with an edge crack as indicated in Fig. 2a.

boundary (dash line) on Fig. 1a. The stress distribution on the cut out rectangular boundary can be obtained with accuracy by the ordinary coarse finite element mesh. Once we have obtained the value of the boundary weight function for the rectangular cracked plate geometry, we only need to integrate over the distributed stress and weight function on the rectangular boundary to obtain the solution for the stress intensity factor. We will follow a similar procedure as described in [13] to construct the explicit form of the mixed mode boundary weight function. These explicit weight functions are expressed in terms of the nondimensional quantities of position coordinate on the boundary. The rectangular cracked geometries considered are single edge crack and central crack. These explicit weight functions are then used to calculate the 


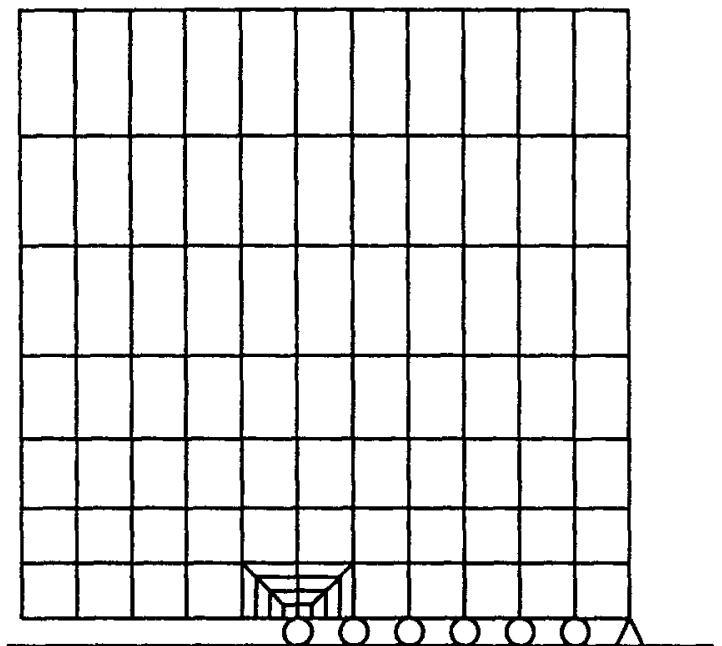

Fig. 3. Finite element mesh representation of one half of the cracked plate.

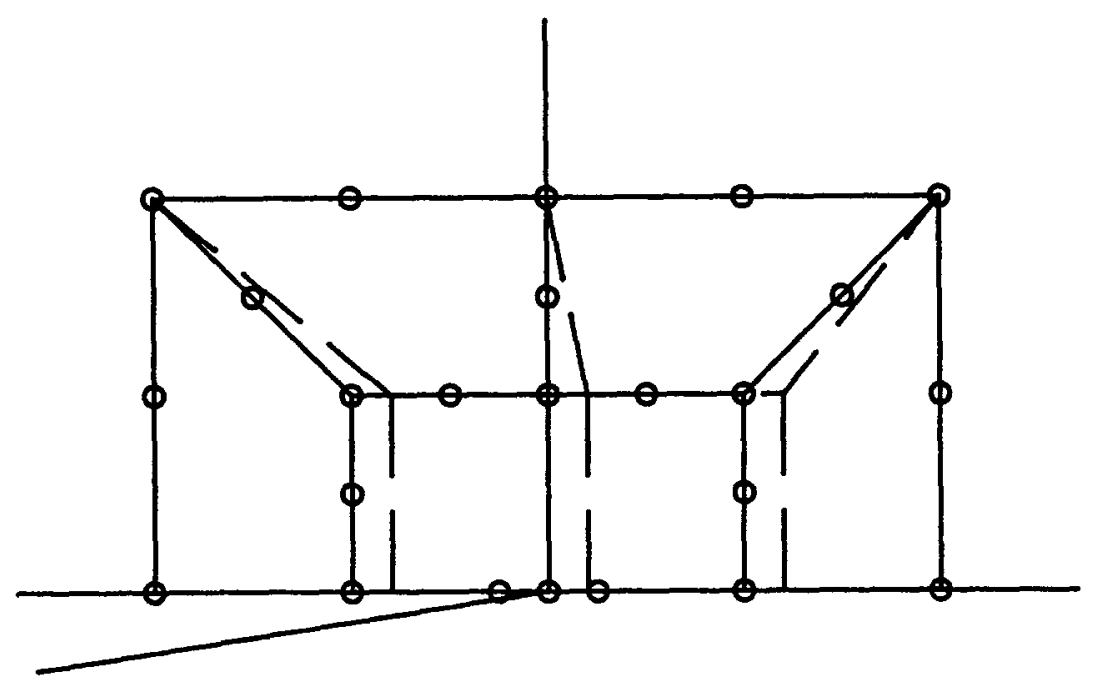

Fig. 4. The quarter-point quadratic isoparametric element at the crack tip.

stress intensity factors for some specific crack problems and compared with known results in the literature.

\section{Weight function formulation and numerical technique}

The weight function method as presented by Bueckner [4] and Rice [5] was used to compute mode I stress intensity factor of symmetric cracked bodies with symmetric loading. Bowie and Freese [6] and Bortman and Banks-Sills [7] extended Rice's displacement derivative definition of the weight function for mode I deformation to mixed fracture mode and mixed boundary conditions. The stress intensity factor is expressed as a product of the applied load and the weight function as follows

$$
K_{\mathrm{I}}=\int_{S_{t}} \mathbf{t}^{*} \cdot \mathbf{h}_{\mathrm{I}} \mathrm{d} s+\int_{S_{u}} \mathbf{u}^{*} \cdot \mathbf{h}_{\mathrm{I}}^{u} \mathrm{~d} s,
$$




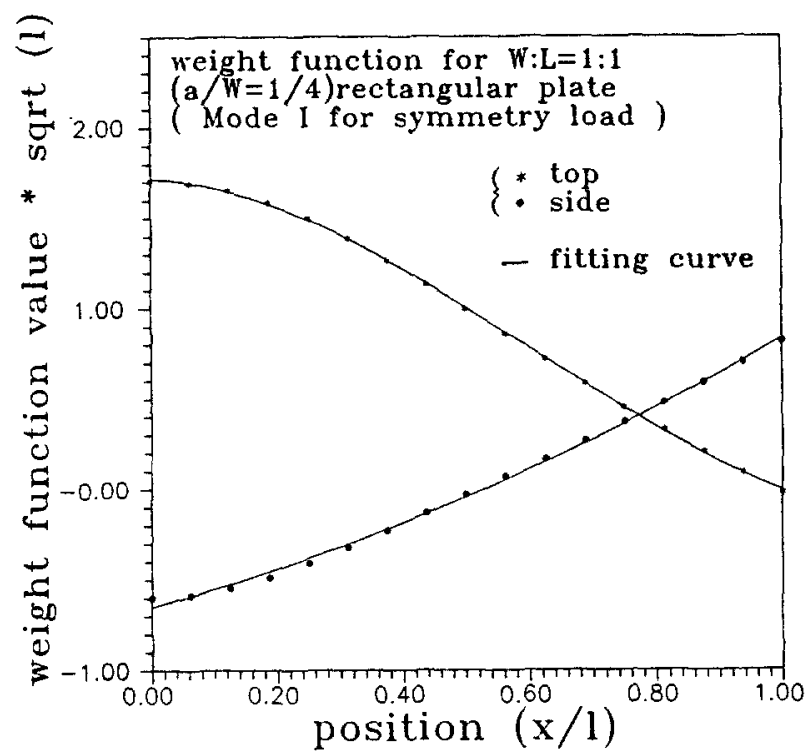

Fig. 5. Boundary weight function for mode I stress intensity factor of a rectangular cracked plate with a central crack and subjected to symmetric loading.

Table 2. The interpolation coefficients $C_{n}$ of the boundary weight function for a rectangular plate with central crack $\left(L / W=\frac{3}{4}, a / W=\frac{1}{4}\right)$ subjected to symmetric loading.

\begin{tabular}{|c|c|c|r|}
\hline \multicolumn{5}{|c|}{$C_{n}\left(L / W=\frac{3}{4}, a / W=\frac{1}{4}\right)$} \\
\hline \multicolumn{2}{|c|}{ top in normal direction } & \multicolumn{2}{|c|}{ top in shear direction } \\
\hline 1 & $0.2245746206 \mathrm{D}+01$ & 1 & $0.5597732290 \mathrm{D}-03$ \\
2 & $0.2640003277 \mathrm{D}+00$ & 2 & $0.2988102927 \mathrm{D}+01$ \\
3 & $-0.9921531682 \mathrm{D}+01$ & 3 & $0.1385438465 \mathrm{D}+01$ \\
4 & $0.9697101940 \mathrm{D}+01$ & 4 & $-0.1385396250 \mathrm{D}+02$ \\
5 & $-0.1160177869 \mathrm{D}+01$ & 5 & $0.1612339119 \mathrm{D}+02$ \\
6 & $-0.1546226706 \mathrm{D}+01$ & 6 & $-0.5747235540 \mathrm{D}+01$ \\
\hline side in normal direction & \multicolumn{3}{|c|}{ side in shear direction } \\
\hline 1 & $-0.5167887193 \mathrm{D}+00$ & 1 & $0.9892529626 \mathrm{D}-04$ \\
2 & $-0.2854222027 \mathrm{D}-01$ & 2 & $-0.8367602736 \mathrm{D}+00$ \\
3 & $0.2547995543 \mathrm{D}+01$ & 3 & $-0.7692989933 \mathrm{D}-02$ \\
4 & $-0.1353066864 \mathrm{D}+01$ & 4 & $0.1526042714 \mathrm{D}+01$ \\
5 & $-0.3560092284 \mathrm{D}-01$ & 5 & $-0.1514466233 \mathrm{D}+01$ \\
6 & $0.1625035261 \mathrm{D}+00$ & 6 & $0.4708122711 \mathrm{D}+00$ \\
\hline
\end{tabular}

$$
K_{\mathrm{II}}=\int_{S_{t}} \mathbf{t}^{*} \cdot \mathbf{h}_{\mathrm{II}} \mathrm{d} s+\int_{S_{u}} \mathbf{u}^{*} \cdot \mathbf{h}_{\mathrm{II}}^{u} \mathrm{~d} s
$$

The decoupled weight function vectors for mode I and mode II can be represented as follows

$$
\mathbf{h}_{\mathrm{I}}=\frac{H}{2 K}\left(K_{\mathrm{II}}^{(2)} \frac{\partial \mathbf{u}^{(1)}}{\partial a}-K_{\mathrm{II}}^{(1)} \frac{\partial \mathbf{u}^{(2)}}{\partial a}\right)
$$



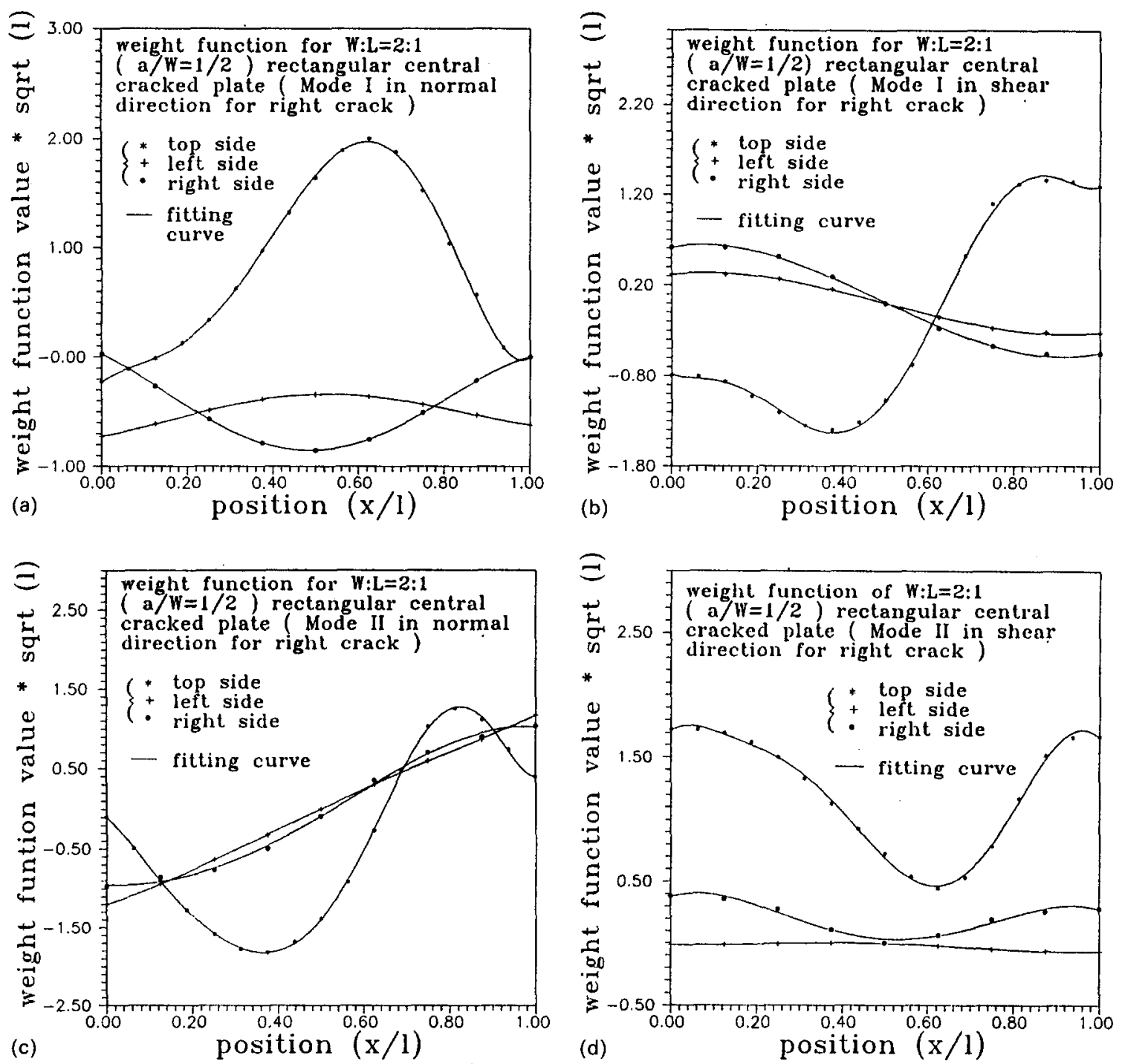

Fig. 6. (a) Boundary weight function for mode I stress intensity factor of a rectangular cracked plate with a central crack and subjected to normal loading; (b) Boundary weight function for mode I stress intensity factor of a rectangular cracked plate with a central crack and subjected to shear loading; (c) Boundary weight function for mode II stress intensity factor of a rectangular cracked plate with a central crack and subjected to normal loading; (d) Boundary weight function for mode II stress intensity factor of a rectangular cracked plate with a central crack and subjected to shear loading.

$$
\begin{aligned}
& \mathbf{h}_{\mathrm{I}}^{u}=-\frac{H}{2 K}\left(K_{\mathrm{II}}^{(2)} \frac{\partial \mathbf{t}^{(1)}}{\partial a}-K_{\mathrm{II}}^{(1)} \frac{\partial \mathbf{t}^{(2)}}{\partial a}\right), \\
& \mathbf{h}_{\mathrm{II}}=\frac{H}{2 K}\left(K_{\mathrm{I}}^{(1)} \frac{\partial \mathbf{u}^{(2)}}{\partial a}-K_{\mathrm{I}}^{(2)} \frac{\partial \mathbf{u}^{(1)}}{\partial a}\right), \\
& \mathbf{h}_{\mathrm{II}}^{u}=-\frac{H}{2 K}\left(K_{\mathrm{I}}^{(1)} \frac{\partial \mathbf{t}^{(2)}}{\partial a}-K_{\mathrm{I}}^{(2)} \frac{\partial \mathbf{t}^{(1)}}{\partial a}\right),
\end{aligned}
$$



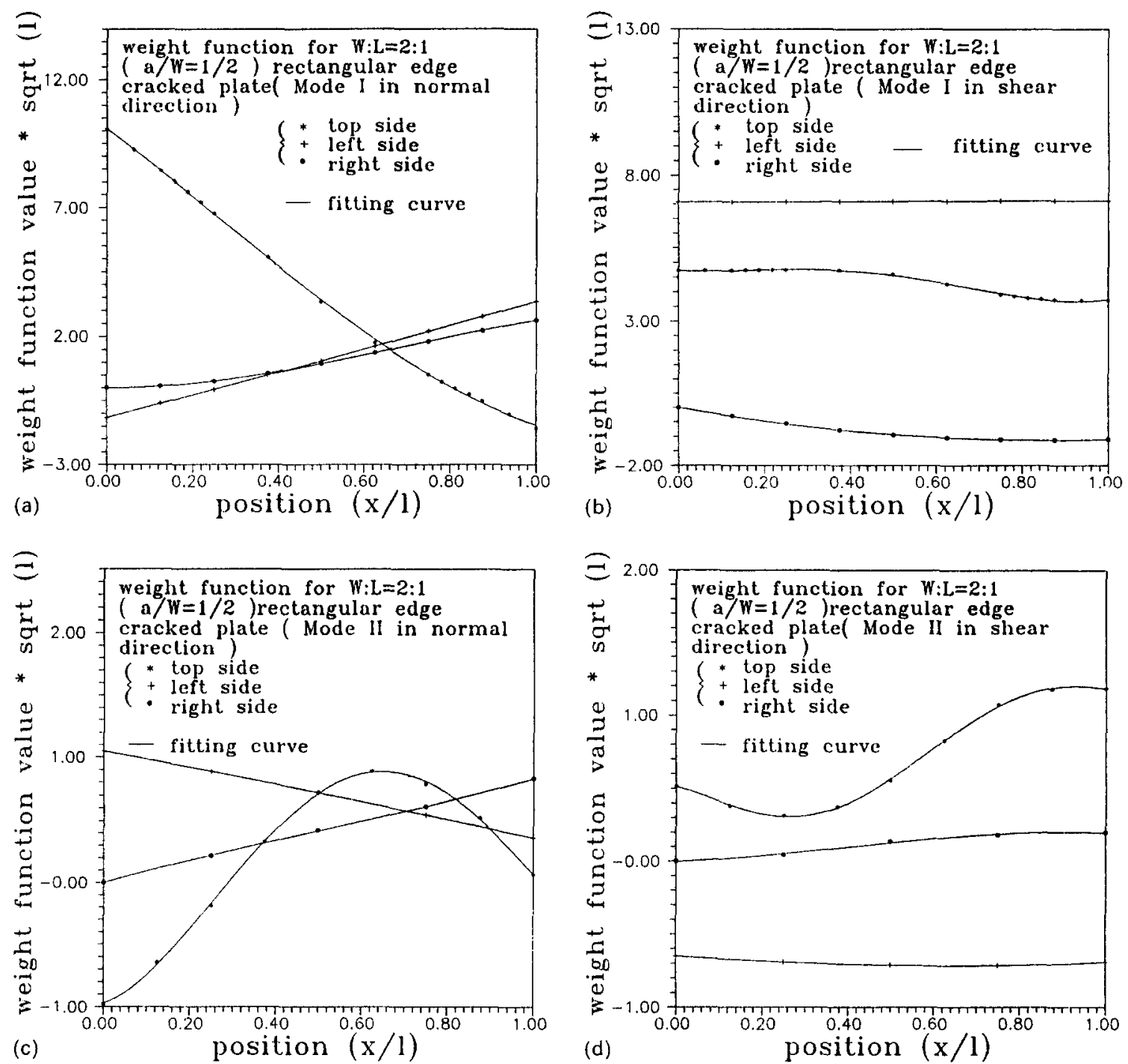

Fig. 7. (a) Boundary weight function for mode I stress intensity factor of a rectangular cracked plate with an edge crack and subjected to normal loading; (b) Boundary weight function for mode I stress intensity factor of a rectangular cracked plate with an edge crack and subjected to shear loading; (c) Boundary weight function for mode II stress intensity factor of a rectangular cracked plate with an edge crack and subjected to normal loading; (d) Boundary weight function for mode II stress intensity factor of a rectangular cracked plate with an edge crack and subjected to shear loading.

and

$$
K=K_{\mathrm{I}}^{(1)} K_{\mathrm{II}}^{(2)}-K_{\mathrm{I}}^{(2)} K_{\mathrm{II}}^{(1)} \neq 0,
$$

in which $H=E$ (Young's modulus) for generalized plane stress and $H=E /\left(1-\nu^{2}\right)$ for plane strain, $\nu$ being Poisson's ratio. The subscript $I$ in $\mathbf{h}_{\mathbf{I}}$ is used to denote the mode I weight function. The boundary has been divided into the part for specified traction $S_{t}$ and that for specified displacement $S_{u}$. Configurations '(1)' and '(2)' are geometrically equivalent to the original problem. The corresponding stress intensity factors and displacement vectors will be 


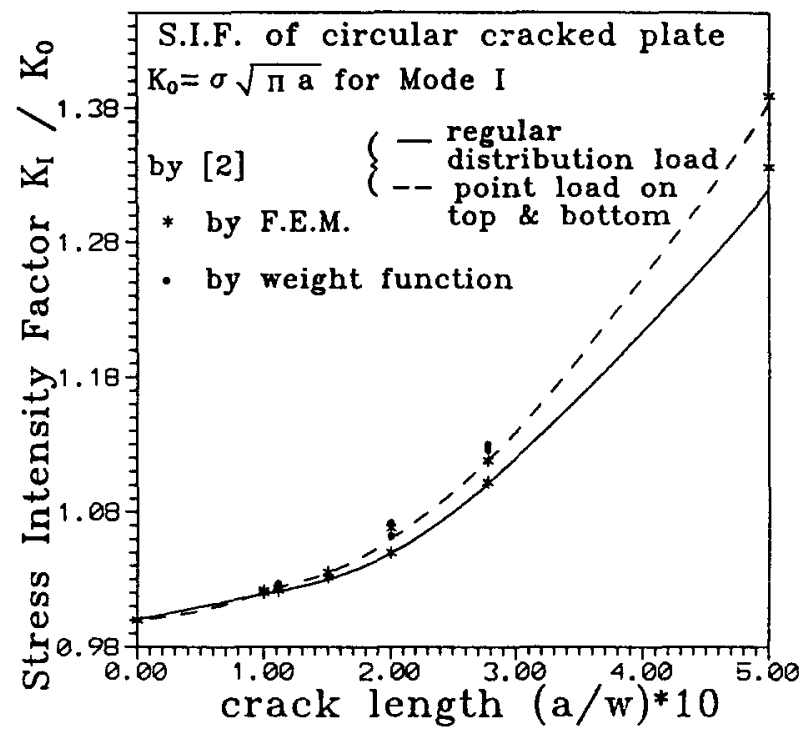

Fig. 8. Comparison of normalized mode I stress intensity factors calculated from the boundary weight function method and other results for a circular disk containing a central crack.

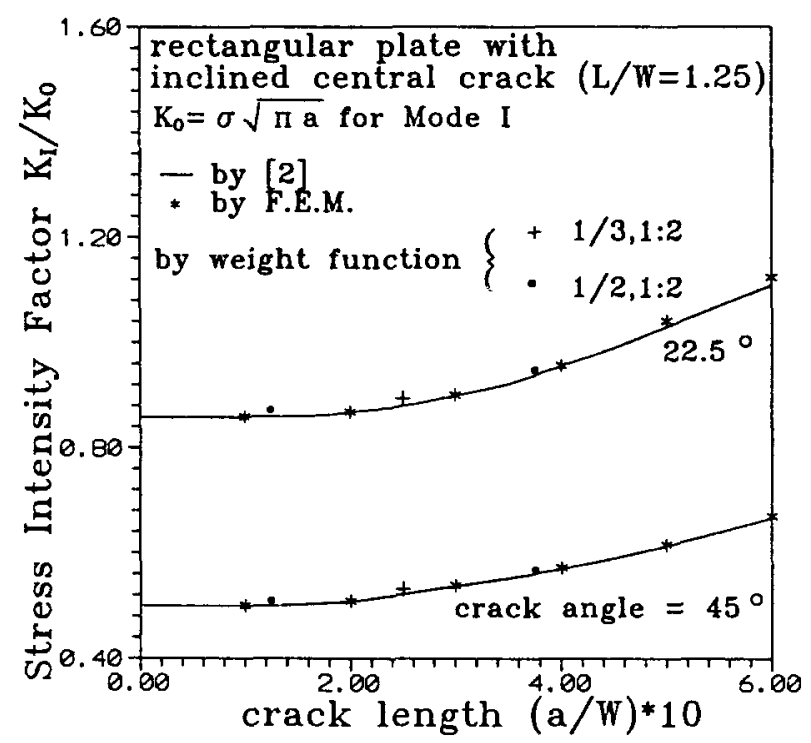

Fig. 9. Comparison of normalized mode I stress intensity factors calculated from the boundary weight function method and other results for a rectangular plate $(L / W=1.25)$ containing an inclined central crack subjected to remote tension condition.

denoted by $K_{\mathrm{I}(\mathrm{II})}^{(1)}, \mathbf{u}^{(1)}$ and $K_{\mathrm{I}(\mathrm{II})}^{(2)}, \mathbf{u}^{(2)}$, respectively. Once the weight functions are determined from the solution for any particular load system, the stress intensity factor induced by any other load system can be obtained from (1) and (2). 
Table 3. The interpolation coefficients $C_{n}$ (mode I) of the boundary weight function for a rectangular plate with central crack $\left(L / W=\frac{1}{2}, a / W=\frac{1}{2}\right)$

\begin{tabular}{|l|r|l|r|}
\hline \multicolumn{4}{|c|}{$C_{n}\left(L / W=\frac{1}{2}, a / W=\frac{1}{2}\right)$} \\
\hline \multicolumn{2}{|c|}{ top in normal direction } & \multicolumn{2}{|c|}{ top in shear direction } \\
\hline 1 & $-0.1530913728 \mathrm{D}+00$ & 1 & $0.4855073177 \mathrm{D}+00$ \\
2 & $-0.9425032440 \mathrm{D}+01$ & 2 & $0.1393668263 \mathrm{D}+01$ \\
3 & $0.8148607831 \mathrm{D}+02$ & 3 & $-0.2795197374 \mathrm{D}+02$ \\
4 & $-0.1198652678 \mathrm{D}+03$ & 4 & $0.7024329309 \mathrm{D}+02$ \\
5 & $0.4689354544 \mathrm{D}+02$ & 5 & $-0.4178511579 \mathrm{D}+02$ \\
\hline right side in normal direction & \multicolumn{1}{|c|}{ right side in shear direction } \\
\hline 1 & $0.1817351238 \mathrm{D}+01$ & 1 & $0.5763905737 \mathrm{D}+00$ \\
2 & $-0.3938326373 \mathrm{D}+01$ & 2 & $0.9294811236 \mathrm{D}+00$ \\
3 & $-0.9196724051 \mathrm{D}+01$ & 3 & $-0.6246786813 \mathrm{D}+01$ \\
4 & $0.2627010085 \mathrm{D}+02$ & 4 & $0.4164524542 \mathrm{D}+01$ \\
5 & $-0.1313505042 \mathrm{D}+02$ & 5 & $-0.1000322447 \mathrm{D}-11$ \\
\hline left side in normal direction & left side in shear direction \\
\hline 1 & $0.3272486274 \mathrm{D}+00$ & 1 & $0.3193235827 \mathrm{D}+00$ \\
2 & $0.1179648379 \mathrm{D}+01$ & 2 & $0.5025835627 \mathrm{D}+00$ \\
3 & $0.4692198441 \mathrm{D}+01$ & 3 & $-0.3423692184 \mathrm{D}+01$ \\
4 & $-0.1174369364 \mathrm{D}+02$ & 4 & $0.2282461456 \mathrm{D}+01$ \\
5 & $0.5871846820 \mathrm{D}+01$ & 5 & $-0.2530956537 \mathrm{D}-12$ \\
\hline
\end{tabular}

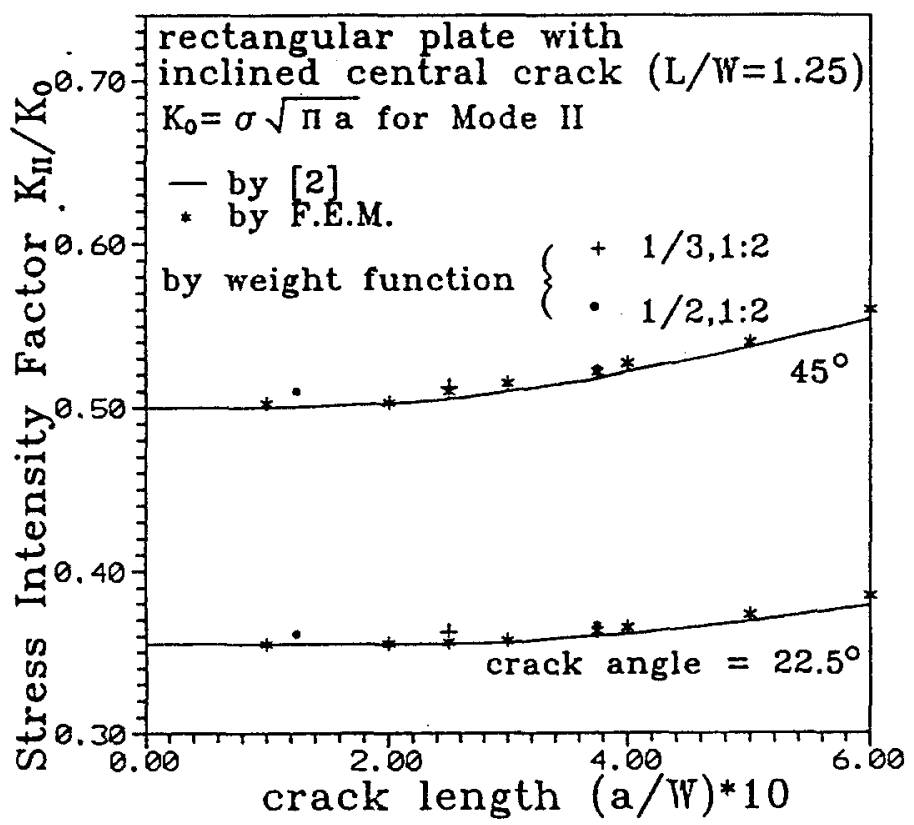

Fig. 10. Comparison of normalized mode II stress intensity factors calculated from the boundary weight function method and other results for a rectangular plate $(L / W=1.25)$ containing an inclined central crack subjected to remote tension condition. 


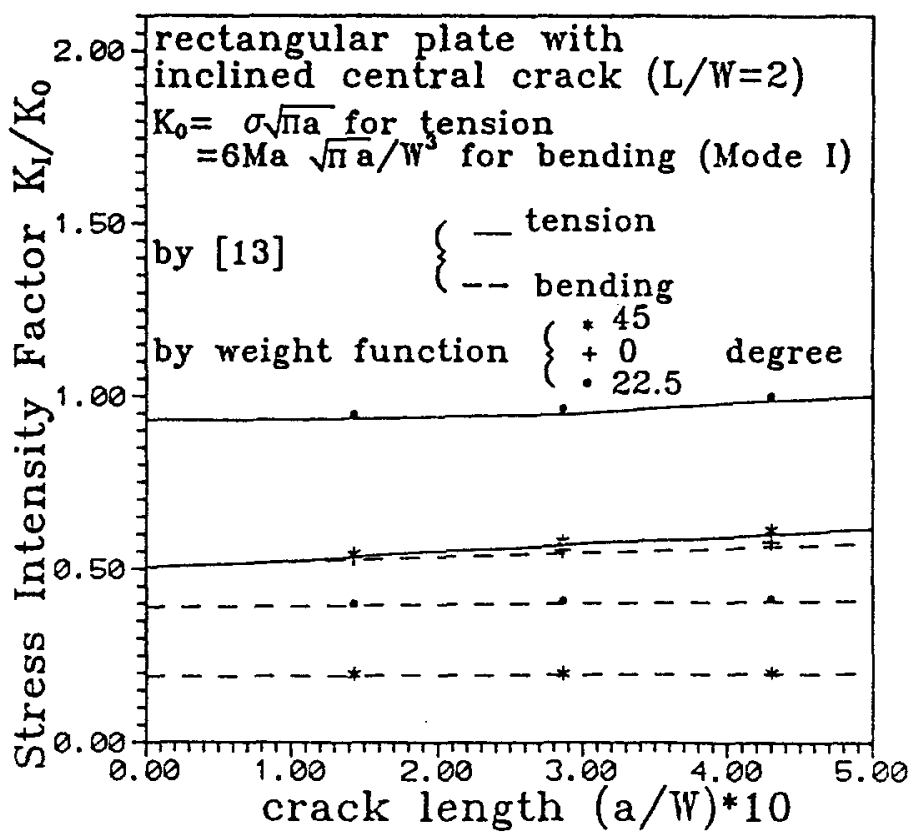

Fig. 11. Comparison of normalized mode I stress intensity factors calculated from the boundary weight function method and other results for a rectangular plate $(L / W=2)$ containing an inclined central crack subjected to remote tension and bending condition.

In this paper, only the traction boundary condition is considered, hence $\mathbf{h}_{I}^{u}$ and $\mathbf{h}_{\mathrm{II}}^{u}$ will vanish. The mode I weight function vector $h_{\mathrm{I}}$ consists of $h_{\mathrm{I} x}$ and $h_{\mathrm{I} y}$ components, which are defined as

$$
\begin{aligned}
& h_{\mathrm{I} x}=\frac{H}{2 K}\left(K_{\mathrm{II}}^{(2)} \frac{\partial u_{x}^{(1)}}{\partial a}-K_{\mathrm{II}}^{(1)} \frac{\partial u_{x}^{(2)}}{\partial a}\right), \\
& h_{\mathrm{I} y}=\frac{H}{2 K}\left(K_{\mathrm{II}}^{(2)} \frac{\partial u_{y}^{(1)}}{\partial a}-K_{\mathrm{II}}^{(1)} \frac{\partial u_{y}^{(2)}}{\partial a}\right),
\end{aligned}
$$

where $u_{x}^{(1)}, u_{x}^{(2)}$ and $u_{y}^{(1)}, u_{y}^{(2)}$ are the displacement components along the $x$ - and $y$-axes, respectively. The corresponding mode II weight functions $h_{\mathrm{II} x}$ and $h_{\mathrm{II} y}$ have similar forms to (7) and (8), which are

$$
\begin{aligned}
& h_{\mathrm{II} x}=\frac{H}{2 K}\left(K_{\mathrm{I}}^{(1)} \frac{\partial u_{x}^{(2)}}{\partial a}-K_{\mathrm{I}}^{(2)} \frac{\partial u_{x}^{(1)}}{\partial a}\right), \\
& h_{\mathrm{II} y}=\frac{H}{2 K}\left(K_{\mathrm{I}}^{(1)} \frac{\partial u_{y}^{(2)}}{\partial a}-K_{\mathrm{I}}^{(2)} \frac{\partial u_{y}^{(1)}}{\partial a}\right) .
\end{aligned}
$$

The weight functions are defined for the boundary of the cracked body as indicated in (1) and (2). However, by employing the linear superposition method proposed in this study, only the weight functions along the prospective boundaries of a rectangular cracked plate are of primary interest for evaluating the stress intensity factor. 
Table 4. The interpolation coefficients $C_{n}$ (mode II) of the boundary weight function for a rectangular plate with central $\operatorname{crack}\left(L / W=\frac{1}{2}, a / W=\frac{1}{2}\right)$

\begin{tabular}{|c|c|c|c|}
\hline \multicolumn{4}{|c|}{$C_{n}\left(L / W=\frac{1}{2}, a / W=\frac{1}{2}\right)$} \\
\hline \multicolumn{2}{|c|}{ top in normal direction } & \multicolumn{2}{|c|}{ top in shear direction } \\
\hline 1 & $0.1586776679 \mathrm{D}+01$ & & -0.5 \\
\hline & 01 & & - \\
\hline & & & \\
\hline & & & \\
\hline 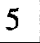 & $0.1743464880 \mathrm{D}+02$ & & $-0.5090919951 \mathrm{D}$ \\
\hline \multicolumn{2}{|c|}{ top in normal direction } & \multicolumn{2}{|c|}{ top in shear direction } \\
\hline 1 & $471062 \mathrm{D}+00$ & & -0.102 \\
\hline & & & \\
\hline 3 & $84938 D+01$ & & 0.6723 \\
\hline & 32 & & -0.4482 \\
\hline 3 & $5 \mathrm{D}+$ & & 0.17055 \\
\hline \multicolumn{2}{|c|}{ top in normal direction } & \multicolumn{2}{|c|}{ top in shear direction } \\
\hline 4 & $.4269010584 \mathrm{D}$ & 1 & -0.12 \\
\hline & $D+00$ & & +01 \\
\hline 3 & & 3 & 0.6981 \\
\hline 4 & $990215 D+01$ & 4 & -0.46546 \\
\hline & $0.1065545107 \mathrm{D}+01$ & & $-0.1200248332 \mathrm{D}-06$ \\
\hline
\end{tabular}

As indicated in (7)-(10), one needs an efficient means for solving the reference geometry fracture mechanics problem to obtain the rate of change in boundary displacements and stress intensity factors. Unfortunately, the exact solution of the displacement field is available only for very few ideal crack problems. An efficient finite element method for determining both the stress intensity factors and weight functions for the cracked body of interest has been achieved by combining the singular crack-tip elements with the virtual crack extension technique.

Because of the computational efficiency, the virtual crack extension technique suggested in [10] and [11] has been widely used in the finite element evaluation of mode I stress intensity factors. The virtual crack extension is a devised algorithm for the efficient calculation of the strain energy release rate of a cracked body. Several authors [20,21] applying this technique to the asymmetric mixed-mode fracture problems found there was a problem in separating mode I and mode II stress intensity factors uniquely. Numerical computation of the weight function requires two virtual crack extensions. Recently, the use of analytical separation of the crack-tip field into mode I and mode II components with the symmetric mesh in the crack tip neighborhood was proposed by Ishikawa [22] and Sha [23] and Sha and Yang [9]. They extended this efficient finite element methodology from mode I cracks to mixed mode cracks for the determination of the stress intensity factors and the nodal weight functions on crack faces by only one virtual crack extension. This is accomplished through the use of symmetric mesh, which provides the decoupling characteristics of the stress, strain and displacement field into mode I and mode II components in the crack-tip neighborhood. The method described above is used in [13] for evaluating oblique edge crack and oblique central crack weight functions on crack faces. There are eight weight functions which should be determined on upper and lower crack faces. Four of them have the square root singular behavior near the 


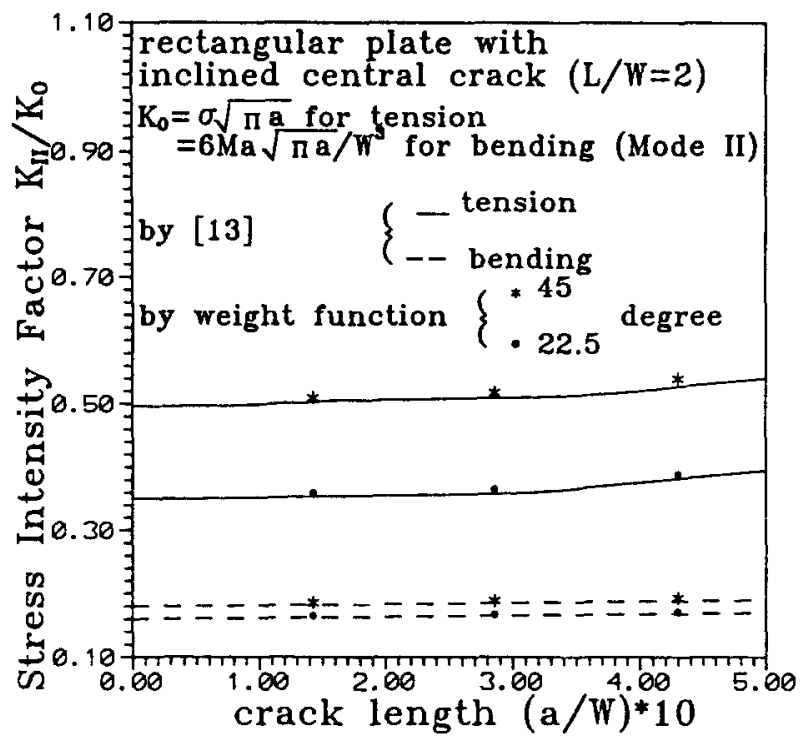

Fig. 12. Comparison of normalized mode II stress intensity factors calculated from the boundary weight function method and other results for a rectangular plate $(L / W=2)$ containing an inclined central crack subjected to remote tension and bending condition.

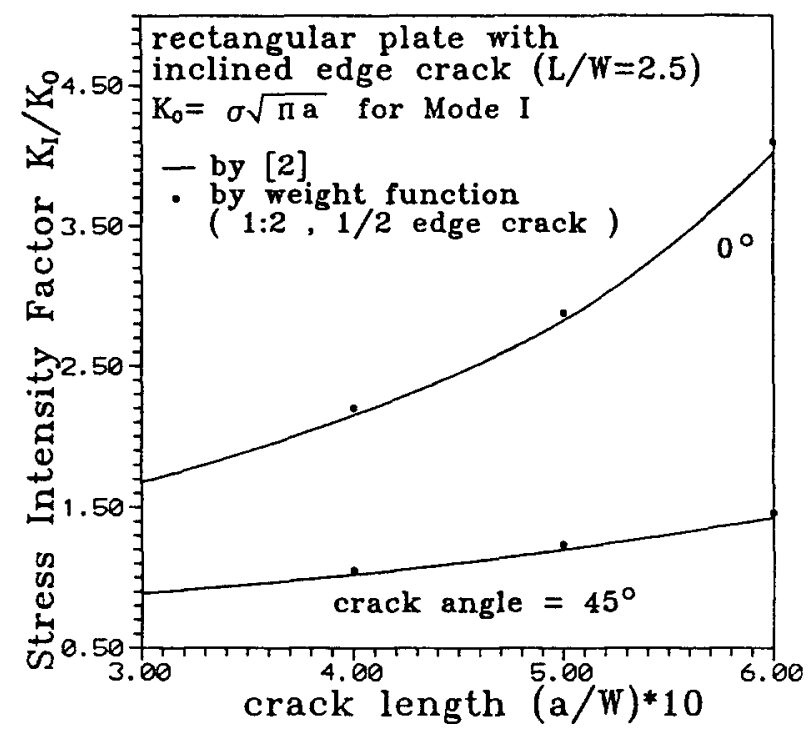

Fig. 13. Comparison of normalized mode I stress intensity factors calculated from the boundary weight function method and other results for a rectangular plate $(L / W=2.5)$ containing an inclined edge crack subjected to remote tension condition.

crack-tip neighborhood, while the other four are nonsingular in the crack-tip neighborhood. By using the principle of superposition, the stress intensity factor under crack-face loading is equivalent to the cracked body with remote loading that produces the same pressure loading on the prospective crack face in the absence of the crack. Hence, for a special specified regular cracked geometry, only the weight functions on the crack faces are needed for evaluating the stress intensity factors. However, for calculating the stress intensity factors of arbitrary cracked geometries, the usually used crack-face weight function concept will not be a suitable 
Table 5. The interpolation coefficients $C_{n}$ (mode I) of the boundary weight function for a rectangular plate with edge crack $\left(L / W=\frac{1}{2}, a / W=\frac{1}{2}\right)$

\begin{tabular}{|c|c|c|c|}
\hline \multicolumn{4}{|c|}{$C_{n}\left(L / W=\frac{1}{2}, a / W=\frac{1}{2}\right)$} \\
\hline \multicolumn{2}{|c|}{ top in normal direction } & \multicolumn{2}{|c|}{ top in shear direction } \\
\hline 1 & $0.1000811196 \mathrm{D}+02$ & 1 & $0.4736616220 \mathrm{D}+01$ \\
\hline 2 & $-0.1092210339 D+02$ & 2 & $-0.6675146967 D+00$ \\
\hline 3 & $-0.1307265038 \mathrm{D}+02$ & 3 & $0.7014385547 \mathrm{D}+01$ \\
\hline 4 & $0.2031891303 D+02$ & 4 & $-0.1814563380 D+02$ \\
\hline 5 & $-0.7855993440 \mathrm{D}+01$ & 5 & $0.1080493208 \mathrm{D}+02$ \\
\hline \multicolumn{2}{|c|}{ right side in normal direction } & \multicolumn{2}{|c|}{ right side in shear direction } \\
\hline 1 & $0.2146162096 \mathrm{D}-02$ & 1 & $0.3674082524 \mathrm{D}-03$ \\
\hline 2 & $-0.2091114887 \mathrm{D}+00$ & 2 & -0.23548 \\
\hline 3 & $0.5846467905 \mathrm{D}+01$ & 3 & $-0.2420140453 \mathrm{D}+00$ \\
\hline 4 & $-0.3499576352 \mathrm{D}+01$ & 4 & $0.3159719599 D+01$ \\
\hline 5 & $0.4834051976 \mathrm{D}+00$ & 5 & $-0.1671149107 \mathrm{D}+01$ \\
\hline \multicolumn{2}{|c|}{ left side in normal direction } & \multicolumn{2}{|c|}{ left side in shear direction } \\
\hline 1 & $-0.1162150987 \mathrm{D}+01$ & 1 & $0.7074337454 \mathrm{D}+01$ \\
\hline 2 & $0.4410015530 \mathrm{D}+01$ & 2 & -0.22124 \\
\hline 3 & $-0.1497008516 D+00$ & 3 & $0.2161286236 \mathrm{D}+00$ \\
\hline 4 & $0.5211234028 \mathrm{D}+00$ & 4 & $-0.2069297605 \mathrm{D}+00$ \\
\hline 5 & $-0.2737229630 \mathrm{D}+00$ & 5 & $0.4881558125 \mathrm{D}-01$ \\
\hline
\end{tabular}

method. In this study, we have introduced the boundary weight function method to calculate the stress intensity factors for arbitrary cracked geometries subjected to general boundary condition on the boundary. A general two-dimensional finite element alternating method for the determination of weight functions for isotropic or orthotropic cracked structures, subjected to mixed mode loading is proposed by Chen and Atluri [24]. The key step in this alternating method is the analytical solution for an embedded crack, subjected to arbitrary crack-face tractions in an infinite medium.

Consider a cracked body with general boundary condition applied on the boundary as shown in Fig. 1a, which will induce normal and shear stresses along a regular specified rectangular boundary. The stress intensity factors of the original problem are equal to that of the cut out regular rectangular cracked plate with central crack subjected to equal stress distribution on the rectangular boundary of Fig. 1a. However, the cut out rectangular cracked plate could also be an edge crack, as shown in Fig. 2a. Hence the problem for the cases of rectangular plate with central and edge crack shown in Fig. $1 \mathrm{~b}$ and Fig. $2 \mathrm{~b}$ are of special interest. Once the weight functions along the rectangular boundary are determined, the stress intensity factors can be easily obtained by simple integrations over the distributed stress and the boundary weight function.

\section{Boundary weight functions for finite rectangular cracked plates}

In order to determine the boundary weight functions, reference stress intensity factor together with the displacement field along the boundary must be known. Exact solutions of the displacement field are available for only a very few crack problems. For most cases of practical 


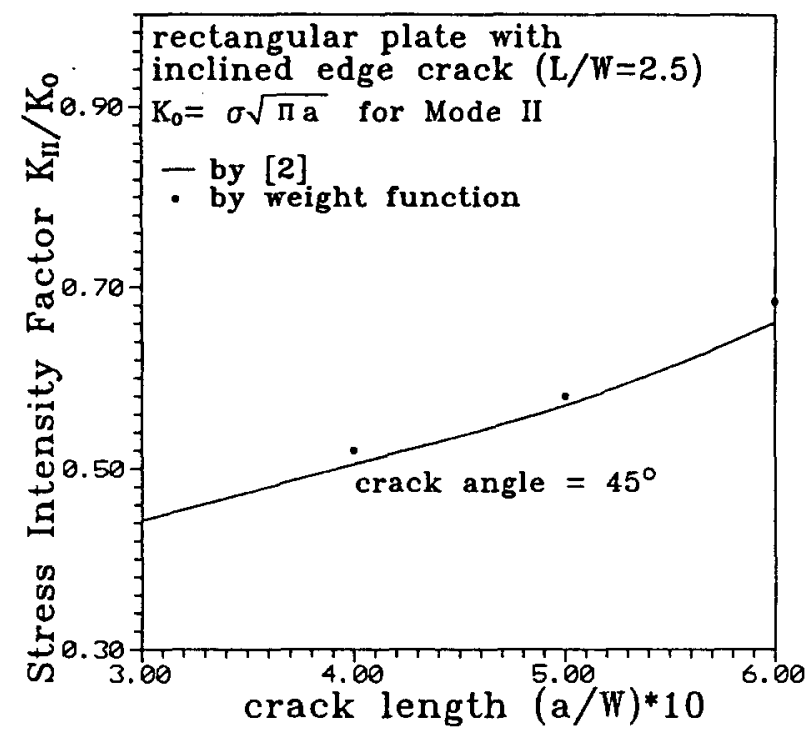

Fig. 14. Comparison of normalized mode II stress intensity factors calculated from the boundary weight function method and other results for a rectangular plate $(L / W=2.5)$ containing an inclined edge crack subjected to remote tension condition.

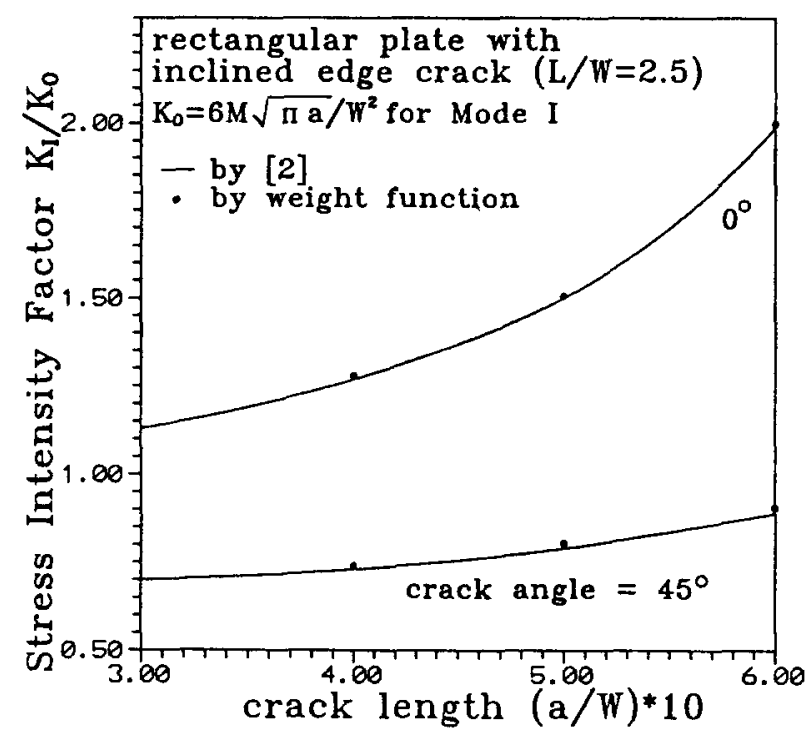

Fig. 15. Comparison of normalized mode I stress intensity factors calculated from the boundary weight function method and other results for a rectangular plate $(L / W=2.5)$ containing an inclined edge crack subjected to bending condition.

interest, exact solutions hardly exist. Hence, good approximations to the displacement field for such cases are very useful for constructing the explicit form of weight function. The evaluation of the weight function requires the calculation of both the stress intensity factor and the displacement derivatives. For specimens with finite dimension, the calculations are usually done by finite element method. Because of the invariant characteristics with respect to the loading conditions for a given geometry and constraint conditions, the simplest uniformly distributed loading is used for the finite element evaluation of the explicit weight functions 
Table 6. The interpolation coefficients $C_{n}$ (mode II) of the boundary weight function for a rectangular plate with edge crack $\left(L / W=\frac{1}{2}, a / W=\frac{1}{2}\right)$

\begin{tabular}{|c|r|r|r|}
\hline \multicolumn{4}{|c|}{$C_{n}\left(L / W=\frac{1}{2}, a / W=\frac{1}{2}\right)$} \\
\hline \multicolumn{2}{|c|}{ top in normal direction } & \multicolumn{2}{|c|}{ top in shear direction } \\
\hline 1 & $-0.9500225169 \mathrm{D}+00$ & 1 & $-0.5028792999 \mathrm{D}+01$ \\
2 & $-0.2115390325 \mathrm{D}+01$ & 2 & $0.3726182277 \mathrm{D}+01$ \\
3 & $0.4223344487 \mathrm{D}+00$ & 3 & $0.2477946124 \mathrm{D}+02$ \\
4 & $0.1095182823 \mathrm{D}+02$ & 4 & $-0.4004888272 \mathrm{D}+02$ \\
5 & $-0.8503701096 \mathrm{D}+01$ & 5 & $0.1700304356 \mathrm{D}+02$ \\
\hline right side in normal direction & \multicolumn{3}{|c|}{ right side in shear direction } \\
\hline 1 & $0.3109885456 \mathrm{D}+00$ & 1 & $0.1572939456 \mathrm{D}+00$ \\
2 & $0.7941834055 \mathrm{D}+00$ & 2 & $-0.2680697281 \mathrm{D}+01$ \\
3 & $-0.8567995952 \mathrm{D}+01$ & 3 & $0.7647479829 \mathrm{D}+01$ \\
4 & $0.1554762509 \mathrm{D}+02$ & 4 & $-0.6233881386 \mathrm{D}+01$ \\
5 & $-0.7773812547 \mathrm{D}+01$ & 5 & $0.9620709910 \mathrm{D}+00$ \\
\hline left side in normal direction & \multicolumn{3}{|c|}{ left side in shear direction } \\
\hline 1 & $-0.3510174199 \mathrm{D}+01$ & 1 & $0.1403328905 \mathrm{D}+01$ \\
2 & $-0.3289684807 \mathrm{D}+00$ & 2 & $-0.1985661630 \mathrm{D}+01$ \\
3 & $0.3944556492 \mathrm{D}+00$ & 3 & $-0.1409010072 \mathrm{D}+00$ \\
4 & $-0.3141718999 \mathrm{D}+00$ & 4 & $0.5894034365 \mathrm{D}-01$ \\
5 & $0.1898200734 \mathrm{D}+00$ & 5 & $-0.1116366055 \mathrm{D}-01$ \\
\hline
\end{tabular}

for the boundaries of interest. The finite element evaluation of the crack-face weight functions using the virtual crack extension technique coupled with singular elements has been discussed extensively by Sha [8] and Sha and Yang [9]. We have also used this technique on the finite element evaluation of the explicit boundary weight functions, but the technical details are not repeated here.

The conventional determination of the weight function by several authors $[8,12,13]$ has usually been restricted to crack face only, since the stress intensity factor under crack face loading is equivalent to loading the cracked body with remote loading that produces the same pressure loading on the prospective crack face in the absence of the crack. The general expression of the crack face weight function is derived from the assumed crack opening displacement. These explicit weight functions are expressed in terms of the nondimensional quantities of coordinate $x / a$, crack length $a / W$ and specimen length $L / W$ by [12] for pure mode I and by [13] for mixed mode. The crack face weight function will behave as square root singularity near the crack tip which should be carefully analyzed to get accurate results.

In this study, the weight functions on a cracked rectangular boundary are investigated for calculating the stress intensity factor of arbitrary cracked bodies subjected to general boundary conditions. The mesh of the finite element is the standard eight-nodal quadratic element as shown in Fig. 3. The elements in the vicinity of the crack tip are modeled with the degenerated quarter-point quadratic isoparametric element as shown in Fig. 4, where the dash line represents the virtual crack extension. The quarter-point element is characterized by square root singularity near the crack tip. As indicated by [8], the ratio of the virtual crack extension distance over the crack length equal to $10^{-5}$ is regarded as good for the numerical results and is used in this paper. 
Table 7. Normalized stress intensity factors for an eccentric inclined crack $(H / W=2, a / W=0.2$, $e / W=0.5)$
$K_{\mathrm{I}}=F_{\mathrm{I}} \sigma \sqrt{\pi a}$
c: by center crack weight function
$K_{\mathrm{II}}=F_{\mathrm{Il}} \sigma \sqrt{\pi a}$
e: by edge crack weight function

\begin{tabular}{|l|l|l|l|l|l|l|l|}
\hline \multicolumn{2}{|c|}{} & \multicolumn{5}{|c|}{$F_{\mathrm{I}}$} & \multicolumn{3}{c|}{$F_{\mathrm{II}}$} \\
\hline$\beta$ & Tip & Y. Murakami & W.H. Chen & $\begin{array}{l}\text { Weight } \\
\text { function }\end{array}$ & Y. Murakami & W.H. Chen & $\begin{array}{l}\text { Weight } \\
\text { function }\end{array}$ \\
\hline \multirow{2}{*}{$0^{\circ}$} & $A$ & 1.09 & 1.09 & $1.09949(\mathrm{c})$ & 0.00 & 0.00 & 0.00 \\
\cline { 2 - 8 } & $B$ & 1.06 & 1.09 & $1.0678(\mathrm{e})$ & 0.00 & 0.00 & 0.00 \\
\hline \multirow{2}{*}{$45^{\circ}$} & $A$ & 0.536 & 0.539 & $0.545(\mathrm{c})$ & 0.525 & 0.525 & $0.5328(\mathrm{c})$ \\
\cline { 2 - 8 } & $B$ & 0.536 & 0.539 & $0.550(\mathrm{e})$ & 0.510 & 0.510 & $0.5256(\mathrm{e})$ \\
\hline
\end{tabular}

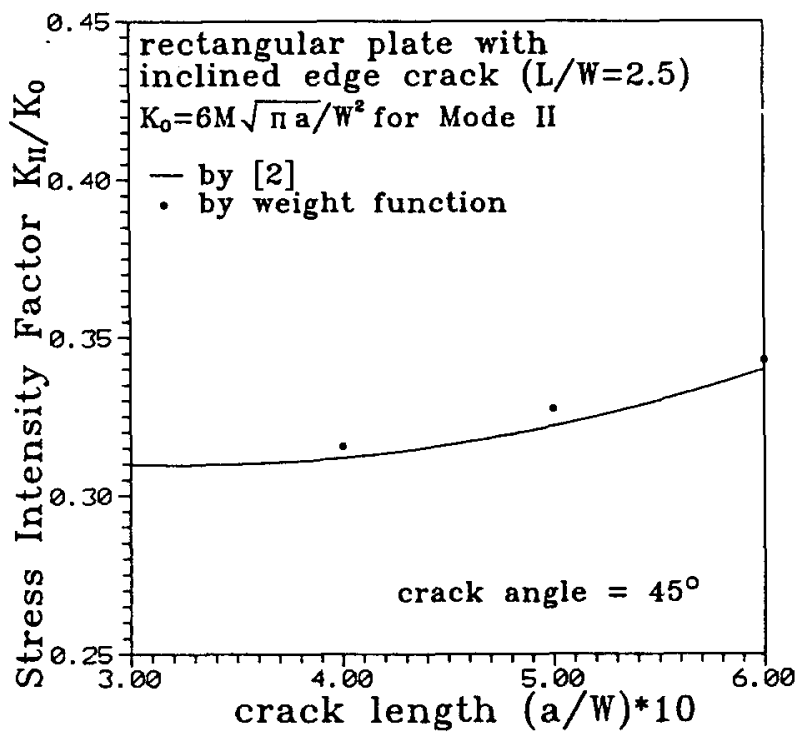

Fig. 16. Comparison of normalized mode II stress intensity factors calculated from the boundary weight function method and other results for a rectangular plate $(L / W=2.5)$ containing an inclined edge crack subjected to bending condition.

The boundary weight function of a rectangular cracked plate with edge and center crack as a function of the four boundaries is taken to have the following polynomial form

$$
\sqrt{l} h(x / l)=\sum_{n=0}^{5} C_{n}(x / l)^{n} .
$$

The variable $l$ represents the length of the boundary, $l=L$ for the boundary along the length of the rectangular plate and $l=W$ for the boundary along the width. The numerical results of the boundary weight functions are calculated by using the finite element method. Since the weight function is universal and is independent of the loading system, the most simple loading system of uniformly distributed tensile loading is chosen for the numerical calculation. The numerical results form the basic data for curve fitting. By using least squares procedure, the discretized values of the boundary weight functions are approximated with (11). The 


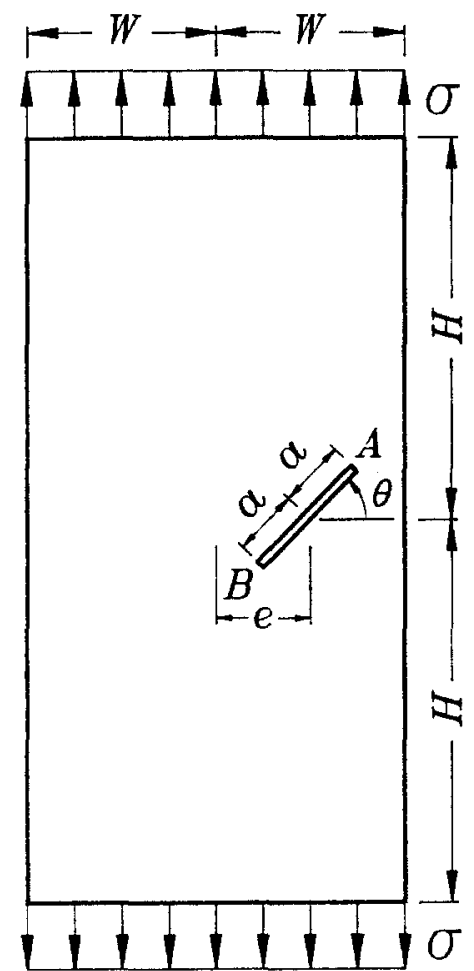

Fig. 17. Geometry of the rectangular plate with an eccentric inclined crack.

tabulation of the coefficients $C_{n}$ for different crack geometries are given in Tables 1-6. Tables 1 and 2 are the results for the center crack subjected to symmetrical loading which will induce only mode I stress intensity factor. Because of the symmetry, there are only two boundaries that should be analyzed. Tables 3 and 4 are the results for evaluating mode I and mode II stress intensity factors of a center crack subjected to unsymmetrical loading, respectively. There are three boundaries, i.e. top side, right side and left side, that should be investigated. Tables 5 and 6 are the results of the coefficients $C_{n}$ for evaluating mode I and mode II stress intensity factors of an edge crack, respectively. The tabulation of these coefficients given in Tables 1-6 are found to provide accurate representations of numerical results. The boundary weight functions for different crack geometries are plotted in Figs. 5-7. Figure 5 represents the boundary weight functions of symmetrical center crack for applied loading in the normal direction. Figures $6 \mathrm{a}-6 \mathrm{~d}$ represent the boundary weight functions for the center crack subjected to unsymmetrical loading, and Figs. $7 \mathrm{a}-7 \mathrm{~d}$ represent the results for the edge crack. In these figures, the actual nodal weight functions obtained from finite element analysis are represented by discrete points, and those calculated from the fitted nodal weight functions are plotted as solid lines. The accuracy of the predicted weight functions are checked directly against the finite element results. Excellent agreement between the two results are shown in these figures and this indicates that the fitted weight functions are good approximations to the actual finite element numerical results. The error that results from the process of curve fitting by means of the least squares method is less than 1 percent in general.

These predetermined explicit weight functions as expressed in (11) for finite rectangular cracked plate along the boundaries will be used to evaluate the stress intensity factors for 
arbitrary cracked geometries. The procedure is rather simple, the first step is to evaluate the stress distribution inside the arbitrary cracked geometry along the cut rectangular boundary. Since the rectangular boundary is far away from the crack tip, it will cause no difficulty in obtaining good numerical results for stress distribution along the rectangular boundary. The next step is to combine the predetermined weight function ((11) and Tables 1-6) and the obtained stress distribution along the rectangular boundary, accurate mixed mode stress intensity factors can be economically evaluated by a simple integration according to (1) and (2). In order to demonstrate the accuracy and validity of the weight functions obtained in this paper in determining the stress intensity factors, several crack geometries have been considered and the results will be compared with the findings of earlier studies. We first consider the case that a circular disk of radius $W$ contains a central crack of length $2 a$, the crack is opened by an external distributed loading (or two opposing concentrated point loadings) on the boundary of the circular disc. The results of the stress intensity factors obtained by Rooke [2] and by the boundary weight function method proposed in this study are shown in Fig. 8 . We can see that the agreement of these two results is very good. The next case, a rectangular plate of width $W$ and length $L$ containing an inclined center crack of length $2 a$, is subjected to an uniformly distributed uniaxial tensile stress $\sigma$ at the ends; the crack is located centrally at an angle $\beta$ to the direction of the plate width. The results are shown as curves of $K_{\mathrm{I}} / K_{0}$ and $K_{\mathrm{II}} / K_{0}$ vs. $a / W$ in Figs. 9 and 10, respectively, for various values of $\beta$. The results for pure bending are shown in Figs. 11 and 12. The uniform loading of an inclined edge crack with crack length $a$ in a finite rectangular plate for $L / W=2.5, \beta=0^{\circ}$ and $45^{\circ}$ is selected to compare with the solutions obtained in [2] and the results are shown in Figs. 13 and 14. The results for applying pure bending are presented in Figs. 15 and 16. Finally, a rectangular plate with an eccentric inclined crack under uniform tension $\sigma$ as shown in Fig. 17 is analyzed. Table 7 shows the results of normalized mode I and mode II stress intensity factor $\left(\mathrm{F}_{\mathrm{I}}, \mathrm{F}_{\mathrm{II}}\right)$ for two crack tips. For comparison purposes, the solutions obtained by Chen and Chang [25] and Murakami [26] are also shown in Table 7. Good agreement between the present results and referenced solutions are noted. Comparison of the stress intensity factors calculated by using the above proposed boundary weight functions with the results obtained by others revealed satisfactory and valid accuracy of the boundary weight function method.

\section{Conclusions}

The methods of calculating stress intensity factors based on weight function techniques are efficient and economical, since once the weight function is determined for a given crack geometry, the stress intensity factor for any loading condition can be obtained by a simple integration. For the conventional study on weight function, most investigations are done for the crack face weight function. In this study, the boundary weight function concept is proposed to calculate the mixed mode stress intensity factors for arbitrary shape of cracked geometries subjected to general boundary conditions. Hence the boundary weight function method is more useful in practical applications. The simplest loading condition of uniform tension and an efficient finite element methodology has been achieved for evaluating the boundary weight functions. In order to facilitate the utilization of the discretized nodal boundary weight functions, they are expressed as a function of the boundary for rectangular cracked plates. These empirical equations for the boundary weight functions of rectangular cracked plates has been successfully obtained in this study. The mixed mode stress intensity factors of complicated geometries for cracked bodies subjected to arbitrary applied loadings can be obtained very 
efficiently by combining the stress field along the boundaries of cut rectangular plates with the interpolated boundary weight functions. Very satisfactory results of the stress intensity factors are obtained by the proposed boundary weight function method when compared to known solutions of other workers.

\section{Acknowledgements}

The research support of the Republic of China National Science Council through Grant NSC 80-0210-D002-32 at National Taiwan University is gratefully acknowledged.

\section{References}

1. H. Tada, P.C. Paris and G.R. Irwin, The Stress Analysis of Cracks Handbook, Del Research Corporation, Hellertown, Penna. (1973).

2. D.P. Rooke and D.J. Cartwright, Compendium of Stress Intensity Factors, Her Majesty's Stationery Office, London (1976).

3. G.C. Sih, Handbook of Stress Intensity Factors, Institute of Fracture and Solid Mechanics, Lehigh University (1973).

4. H.F. Bueckner, ZAMM 50 (1970) 529-546.

5. J.R. Rice, International Journal of Solids and Structures 8 (1972) 751-758.

6. O.L. Bowie and C.E. Freese, Engineering Fracture Mechanics 14 (1981) 519-526.

7. Y. Bortman and L. Banks-Sills, Journal of Applied Mechanics 50 (1983) 907-909.

8. G.T. Sha, Engineering Fracture Mechanics 19 (1984) 685-699.

9. G.T. Sha and C.T. Yang, Engineering Fracture Mechanics 21 (1985) 1119-1149.

10. D.M. Parks, International Journal of Fracture 10 (1974) 487-501.

11. T.K. Hellen, International Journal of Numerical Methods in Engineering 9 (1975) 187-207.

12. C.H. Tsai and C.C. Ma, International Journal of Fracture 40 (1989) 43-63.

13. C.C. Ma, Z.S. Chang and C.H. Tsai, Engineering Fracture Mechanics 36 (1990) 267-285.

14. T.L. Sham, International Journal of Solids and Structures 23 (1987) 1357-1372.

15. T.L. Sham and Y. Zhou, International Journal of Fracture 41 (1989) 51-75.

16. Ibid., 40 (1989) 13-41.

17. H.O.K. Kirchner, International Journal of Fracture 31 (1986) 173-181.

18. D. An, International Journal of Fracture 34 (1987) 85-109.

19. H. Gao, International Journal of Fracture 56 (1992) 139-158.

20. T.K. Hellen and W.S. Blackburn, International Journal of Fracture 11 (1975) 605-617.

21. M.L. Vanderglas and R.J. Pick, Fracture 3, Waterloo, Canada (1977) 501-506.

22. H. Ishikawa, International Journal of Fracture 16 (1980) 243-246.

23. G.T. Sha, International Journal of Fracture 25 (1984) 33-42.

24. K.L. Chen and S.N. Atluri, Engineering Fracture Mechanics 36 (1990) 327-340.

25. W.H. Chen and C.S. Chang, Computers and Structures 33 (1989) 1451-1458.

26. Y. Murakami, Engineering Fracture Mechanics 10 (1978) 497-513. 